\title{
Validating a novel index (SWAT-Bp) to predict mortality risk of community-acquired pneumonia in Malawi
}

\author{
Imogen M Buss ${ }^{1}$, Edmund Birkhamshaw ${ }^{2}$, Michael A. Innes ${ }^{3}$, Itai \\ Magadoro $^{4}$, Peter I. Waitt ${ }^{5}$, Jamie Rylance ${ }^{6,7}$ \\ 1. Department of Medicine, North Bristol NHS Trust, Bristol, United Kingdom \\ 2. Department of Infectious Diseases, Heartlands Hospital, Heart of England Foundation Trust, \\ Birmingham, United Kingdom \\ 3. General Practitioner, Stirchley Medical Practice, Telford, United Kingdom \\ 4. Department of Medicine, Queen Elizabeth Central Hospital, Blantyre, Malawi \\ 5. Acute Medical Unit, Wirrall University Hospital Foundation Trust, United Kingdom \\ 6. Senior Clinical Lecturer in respiratory medicine, Liverpool School of Tropical Medicine, United \\ Kingdom \\ 7. Lung Health Group Lead, Malawi-Liverpool-Wellcome Program, Blantyre, Malawi
}

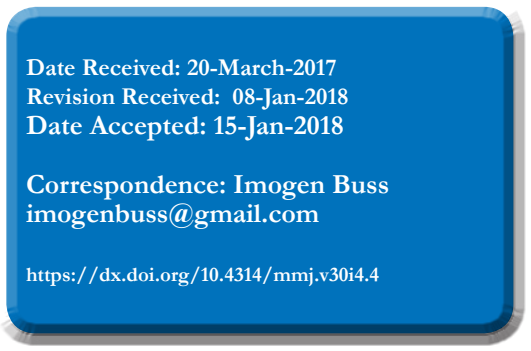

\begin{abstract}
Background
Abstract

Community-acquired pneumonia is a major cause of mortality worldwide. Early assessment and initiation of management improves outcomes. In higher-income countries, scores assist in predicting mortality from pneumonia. These have not been validated for use in most lower-income countries.

Aim

To validate a new score, the SWAT-Bp score, in predicting mortality risk of clinical community-acquired pneumonia amongst hospital admissions at Queen Elizabeth Central Hospital, Blantyre, Malawi.

Methods

The five variables constituting the SWAT-Bp score (male [S]ex, muscle [W]asting, non-[A] mbulatory, [T] emperature $(>38$ oC or $<35 \mathrm{oC})$ and $[B]$ lood [p]ressure (systolic $<100$ and/or diastolic $<60)$ ) were recorded for all patients with clinical presentation of a lower respiratory tract infection, presumed to be pneumonia, over four months $(\mathrm{N}=216)$. The sensitivity and specificity of the score were calculated to determine accuracy of predicting mortality risk.

Results

Median age was 35 years, HIV prevalence was $84.2 \%$ amongst known statuses, and mortality rate was $12.5 \%$. Mortality for scores $0-5$ was $0 \%, 8.5 \%, 12.7 \%, 19.0 \%, 28.6 \%, 100 \%$ respectively. Patients were stratified into three mortality risk groups dependent on their score. SWAT-Bp had moderate discriminatory power overall (AUROC 0.744 ). A SWAT-Bp score of $\geq 2$ was $82 \%$ sensitive and $51 \%$ specific for predicting mortality, thereby assisting in identifying individuals with a lower mortality risk.

Conclusion

In this validation cohort, the SWAT-Bp score has not performed as well as in the derivation cohort. However, it could potentially assist clinicians identifying low-risk patients, enabling rapid prioritisation of treatment in a low-resource setting, as it helps contribute towards individual patient risk stratification.
\end{abstract}

Key words: community-acquired pneumonia, severity, score, Malawi

\section{Introduction}

Lower respiratory tract infections (LRTIs) are the fourth most common cause of death globally, responsible for 3.1 million deaths annually, and remain the leading cause of death in low-income countries ${ }^{1}$. Pneumonia (LRTI with radiological evidence) accounts for 14\% of deaths in Malawi ${ }^{2}$. At Queen Elizabeth Central Hospital (QECH), Blantyre, Malawi, there are approximately 1500 pneumonia admissions annually, with $20 \%$ in-patient mortality rate $^{3}$, similar to other subSaharan countries ${ }^{4}$. Effective management relies upon rapid assessment, diagnosis and treatment. Accurate early assessment of disease severity is essential to patient triage ${ }^{5-7}$. Determining the need for hospital admission is medically and economically important, and initial assessment influences subsequent management decisions ${ }^{8,9}$. Clinical assessment of pneumonia frequently fails to accurately estimate the risk of clinical deterioration ${ }^{10-12}$. Severity scores provide a structured and objective severity assessment, and can improve the identification of high and low risk patients ${ }^{13,14}$.

Widely-used severity scores include the CURB-65 and CRB-
65 scores $^{10,15,16}$ and the pneumonia severity index (PSI) ${ }^{12}$. These have been validated in many countries including Canada, New Zealand, Spain and Pakistan 5,10,17,18. However, their application in areas of high HIV prevalence, specifically sub-Saharan Africa, is not well studied. Indeed, the eligibility criteria for these scores exclude patients with HIV infection ${ }^{12,16}$. Birkhamshaw et al. showed that the sensitivity of the CRB65 score in a Malawian hospital for a score of $\geq 2$ was low $(36.4 \%)$ compared to the UK $(76.8 \%)^{16,19}$. This renders the CRB-65 score insensitive at predicting pneumonia mortality risk in this setting ${ }^{20}$. Birkhamshaw et al. proposed a novel score (SWAT-Bp) incorporating five variables independently associated with disease ${ }^{19}$. The constituent variables are: male [S]ex; muscle [W] asting; non-[A]mbulatory; [T]emperature $\left(>38^{\circ} \mathrm{C}\right.$ or $\left.<35^{\circ} \mathrm{C}\right)$; [B]lood [p]ressure (Systolic Pressure $<100$ and/or Diastolic Pressure $<60)$. Mortality was positively correlated with overall score. We present prospective data from Malawi against which the SWAT-Bp score is validated. The aim was to describe the sensitivity and specificity of the score in a validation cohort. 


\section{Methods}

The prospective cohort study was conducted on the medical wards of Queen Elizabeth Central Hospital. This 1,000bed government hospital in Blantyre, Malawi, has typical staff ratios of 1 nurse to 50 patients. We approached all consecutive adults ( $\geq 16$ years) admitted between $19^{\text {th }}$ February and $1^{\text {st }}$ April or $6^{\text {th }}$ October and $27^{\text {th }}$ November 2011, with a preliminary clinical diagnosis of communityacquired pneumonia. Patients were included if they had a clinical presentation of LRTI and a presumed primary diagnosis of CAP on admission in accordance with the British Thoracic Society primary care guidelines: (1) symptoms of acute lower respiratory tract illness, (2) new focal chest signs on examination, (3) evidence of systemic illness, (4) no other explanation for the illness and (5) a clinical decision that it should be treated with antibiotics. ${ }^{21}$ Exclusion criteria were: (1) alternative primary admission diagnosis [not CAP], (2) hospitalisation within the preceding 14 days (excluding hospital-acquired pneumonia), (3) pneumonia as an expected terminal event in disseminated Kaposi's sarcoma, and (4) symptoms for more than 21 days. Ethical approval was obtained from the University of Birmingham BMedSc Population Sciences and Humanities Internal Ethics Committee, UK, and the College of Medicine Research and Ethics Committee, Blantyre, Malawi.

\section{Data collection}

Eligibility was confirmed from patient notes within 48 hours

Table 1: Characteristics of participants included in the analysis and those lost to follow-up. Statistical comparisons were made.

\begin{tabular}{|c|c|c|c|c|c|c|c|}
\hline & \multicolumn{2}{|c|}{$\begin{array}{l}\text { Participants } \\
\text { included in } \\
\text { analysis }\end{array}$} & \multicolumn{2}{|c|}{$\begin{array}{l}\text { Participants lost to } \\
\text { follow-up }\end{array}$} & \multicolumn{2}{|l|}{ Comparison } & \multirow[b]{2}{*}{ P-value* } \\
\hline & $\mathrm{N}$ & $\%$ & $\mathrm{~N}$ & $\%$ & Test & Value & \\
\hline Total cohort & 216 & 100 & 18 & 100 & - & - & - \\
\hline Male & 90 & 41.7 & 10 & 55.6 & $x^{2}$ & 1.3 & 0.25 \\
\hline In-hospital Mortalities & 27 & 12.5 & - & - & - & - & - \\
\hline HIV positive ( $\%$ of known) & 144 & 84.2 & 10 & 90.9 & $x^{2}$ & 0.36 & 0.55 \\
\hline HIV unknown & 45 & 20.8 & 7 & 38.9 & $x^{2}$ & 3.1 & 0.078 \\
\hline Median admission (days) & 6 & - & - & - & - & - & - \\
\hline Median age (years) & 35 & - & 32 & - & $\begin{array}{l}\text { Independent Samples } \\
\text { Median }\end{array}$ & 2.96 & 0.086 \\
\hline Age $16-24$ & 35 & 16.2 & 2 & 11.1 & & & \\
\hline Age 25-34 & 67 & 31.0 & 11 & 61.1 & & & \\
\hline Age $35-44$ & 66 & 30.5 & 3 & 16.7 & - & - & - \\
\hline Age 45-54 & 21 & 9.7 & 1 & 5.6 & & & \\
\hline Age $55+$ & 27 & 12.5 & 1 & 5.6 & & & \\
\hline \multicolumn{8}{|l|}{ SWAT-Bp score } \\
\hline 0 & 43 & 19.9 & 2 & 11.1 & \multirow{6}{*}{ - } & \multirow{6}{*}{-} & \multirow{6}{*}{-} \\
\hline 1 & 59 & 27.3 & 6 & 33.3 & & & \\
\hline 2 & 55 & 25.5 & 5 & 27.8 & & & \\
\hline 3 & 42 & 19.4 & 4 & 22.2 & & & \\
\hline 4 & 14 & 6.5 & 0 & 0 & & & \\
\hline 5 & 3 & 1.4 & 1 & 5.6 & & & \\
\hline
\end{tabular}

of admission. The first recorded temperature and blood pressure were used to derive the score. The other variables were measured on enrolment, within 48 hours of admission. Muscle wasting was defined as mid-upper arm circumference (MUAC) $\leq 190 \mathrm{~mm}^{22}$ and non-ambulatory was defined as 'unable to walk unaided'. The MUAC was measured for each patient during enrolment and the ambulatory status by verbal confirmation from the participant or relative (if not documented). Paper based data records were pseudoanonymised using study numbers for confidentiality.

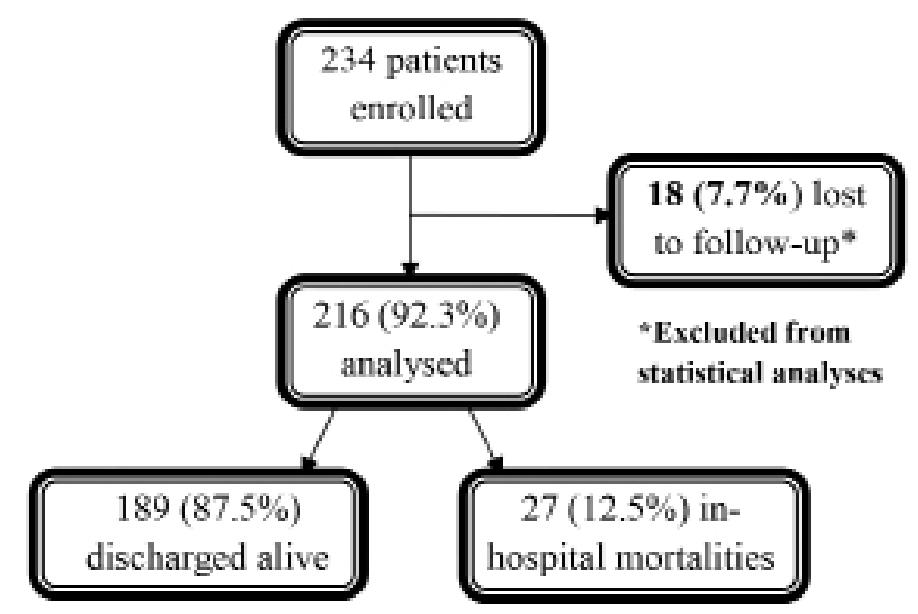

Figure 1: Flow-chart demonstrating the screening and follow-up of study participants
$18(7.7 \%)$ lost

Excluded from statistical analyses 
Patient outcomes were established by daily review and a triangulation of data from ward discharge books, electronic discharge system and paper records office. For analysis, patients were classified as 'alive at discharge' or 'died inhospital'. Those with indeterminable outcomes were excluded from the analysis and deemed lost to follow-up. Inpatients were followed up for a maximum of 30 days or discharge, whichever was sooner. Clinicians treating the patients were not involved in this research study. Hence, they were blinded to the scoring system, and this would not have impacted patient management.

\section{Statistical analyses}

We estimated that from a population of 200 patients, validation of sensitivity would be possible to within $7 \%$ and specificity to within $8.3 \%$, assuming $80 \%$ sensitivity and $75 \%$ specificity ${ }^{16,23}$. Odds ratios of inpatient death were calculated for each variable in the SWAT-Bp score. Sensitivity, specificity, positive predictive values (PPV), negative predictive values (NPV) and area under the receiving operating characteristic (ROC) curve were calculated using PASW Statistics 17 manufactured by IBM.

\section{Results}

Between $19^{\text {th }}$ February $-1^{\text {st }}$ April and $6^{\text {th }}$ October $-27^{\text {th }}$ November 2011, 234 patients with a preliminary diagnosis of community-acquired pneumonia met the eligibility criteria (Figure 1). Of these, 18(7.7\%) were excluded due to loss to follow-up. Of the 216 remaining participants included, 90 $(41.7 \%)$ were male. Mean age was 37 years (median 35, range 16-79). HIV status was unknown for 45 patients (20.8\%); 144 were HIV positive $(84.2 \%$ of known HIV status). Overall inpatient mortality rate was $12.5 \%(27) ; 48 \%$ (13) of these deaths occurred within 48 hours and 70\% (19) within one week of admission. Baseline characteristics were similar between included participants and those lost to follow-up (Table 1).

Table 2: Relationship between the SWAT-Bp score and risk of mortality

\begin{tabular}{|lll|ll|}
\hline SWAT-Bp & Patients N & Mortalities & \multicolumn{2}{|l|}{$95 \%$ Confidence Intervals $(\mathrm{Cl})$} \\
\cline { 4 - 5 } Score & & $\mathrm{N}(\%)$ & Lower & Upper \\
\hline 0 & 43 & $0(0)$ & 0 & 8.2 \\
1 & 59 & $5(8.5)$ & 3.7 & 18.3 \\
2 & 55 & $7(12.7)$ & 6.3 & 24.0 \\
3 & 42 & $8(19.0)$ & 10.0 & 33.3 \\
4 & 14 & $4(28.6)$ & 11.7 & 54.6 \\
5 & 3 & $3(100)$ & 43.8 & 100 \\
\hline
\end{tabular}

The SWAT-Bp score of $\geq 2$ demonstrates a sensitivity of $81.5 \%$ (95\% CI 61.3-93.0) and specificity of $51.3 \%$ (95\% CI 44.0-58.6). The SWAT-Bp score could further divide patients into three groups; $47 \%$ of participants score 0 or 1 with $4.9 \%$ mortality, $26 \%$ of participants score 2 with $12.7 \%$ mortality and $27 \%$ score 3 or above with $25.4 \%$ mortality. The moderate performance of the SWAT-Bp score in predicting mortality risk is demonstrated by the area under the ROC curve of 0.744 . The most significant predictors for mortality were male sex (Odds Ratio 4.0) and being non-ambulatory (Odds Ratio 4.1) (Table 4). For these variables, sensitivity and specificity were $70.4 \%$ and $62.4 \%$ respectively for male sex and $66.7 \%$ and $67.2 \%$ for non-ambulatory status. Negative predictive value was $93.7 \%$ and $93.4 \%$ respectively (Table 3). Figure 2: Graphic representation of the relationship between SWATBp score and inhospital mortality

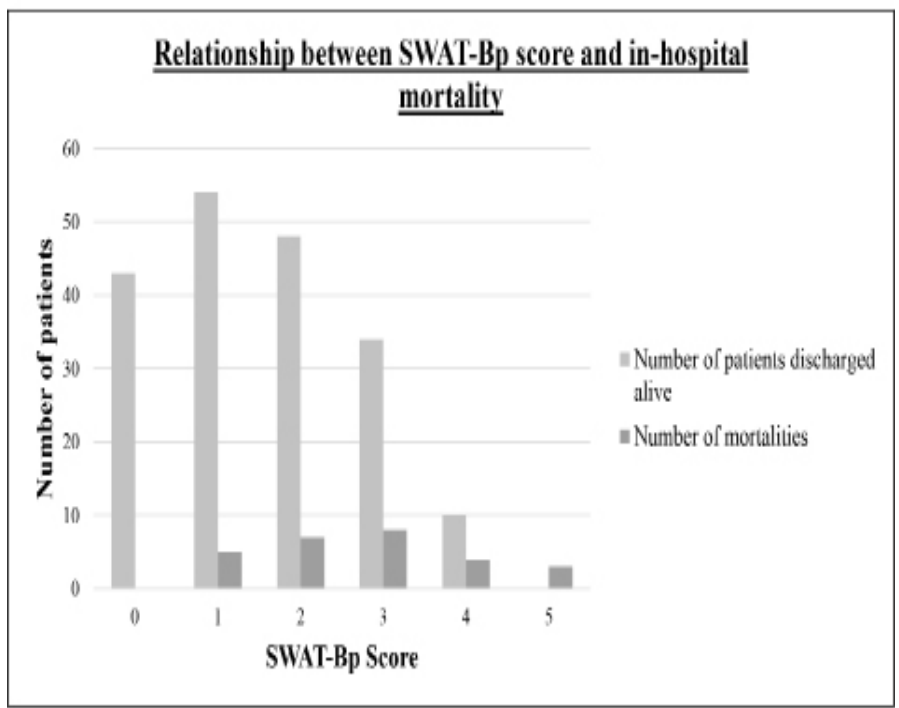

Table 3: Test characteristics for mortality prediction for the SWATBp score

\begin{tabular}{|c|c|c|c|c|}
\hline \multirow{2}{*}{$\begin{array}{l}\text { SWAT-Bp cul-off } \\
\text { point }\end{array}$} & Sensitivity \% & Specificity \% & PPV \% & NPV \% \\
\hline & $(95 \% \mathrm{Cl})$ & $(95 \% \mathrm{Cl})$ & $(95 \% \mathrm{Cl})$ & $(95 \% \mathrm{Cl})$ \\
\hline$\geq 0$ & $100(84.5-100)$ & $0(0-2.5)$ & $12.5(8.5-17.8)$ & - \\
\hline$\geq 1$ & $100(84.5-100)$ & $22.8(17.1-30.0)$ & $15.6(10.7-22.1)$ & $100(89.8-100)$ \\
\hline$\geq 2$ & $81.5(61.3-93.0)$ & $51.3(44.0-58.6)$ & $19.3(12.7-28.0)$ & 95.1 (88.4-98.2) \\
\hline$\geq 3$ & $55.6(35.6-74.0)$ & $76.7(70.0-82.4)$ & $25.4(15.4-38.7)$ & $92.4(86.7-95.8)$ \\
\hline$\geq 4$ & $25.9(11.9-46.6)$ & $94.7(90.2-97.3)$ & $41.2(19.4-66.5)$ & $89.9(84.7-93.6)$ \\
\hline 5 & $11.1(2.9-30.3)$ & $100(97.5-100)$ & $100(31.0-100)$ & $88.7(83.5-92.5)$ \\
\hline Gender & $70.4(49.7-85.5)$ & $62.4(55.1-69.3)$ & $21.1(13.5-31.2)$ & $93.7(87.5-97.0)$ \\
\hline Non-ambulatory & $66.7(46.0-82.8)$ & $67.2(60.0-73.7)$ & $22.5(14.2-33.5)$ & $93.4(87.4-96.7)$ \\
\hline
\end{tabular}

Table 4: Individual predictor variables in the SWAT-Bp score separated by number of patients scoring for that variable, number of mortalities and Odds Ratios

\begin{tabular}{|llllll|}
\hline $\begin{array}{l}\text { Individual SWAT-Bp } \\
\text { Variables }\end{array}$ & $\begin{array}{l}\text { Patients } \\
\text { scoring N }\end{array}$ & $\begin{array}{l}\text { Mortalities } \\
\mathrm{N}(\%)\end{array}$ & $\begin{array}{l}\text { Odds Ratio } \\
\text { (OR) }\end{array}$ & $\begin{array}{l}\text { 95\% } \\
\text { Confidence } \\
\text { Intervals } \\
\text { Lower }\end{array}$ & Upper \\
\hline Gender & 90 & $19(21.1)$ & 4.0 & 1.6 & 9.5 \\
Muscle wasting & 39 & $9(23.1)$ & 2.7 & 1.1 & 6.5 \\
Ambulatory status & 80 & $18(22.5)$ & 4.1 & 1.7 & 9.6 \\
Temperature & 90 & $15(16.7)$ & 1.6 & 0.7 & 3.6 \\
Blood Pressure & 67 & $13(19.4)$ & 2.7 & 1.2 & 6.1 \\
\hline
\end{tabular}

Figure 3 demonstrates how the SWAT-Bp score could be used in clinical practice to help to stratify the mortality risk of patients attending hospital with clinical presentation of a lower respiratory tract infection and a presumed primary diagnosis of pneumonia. 


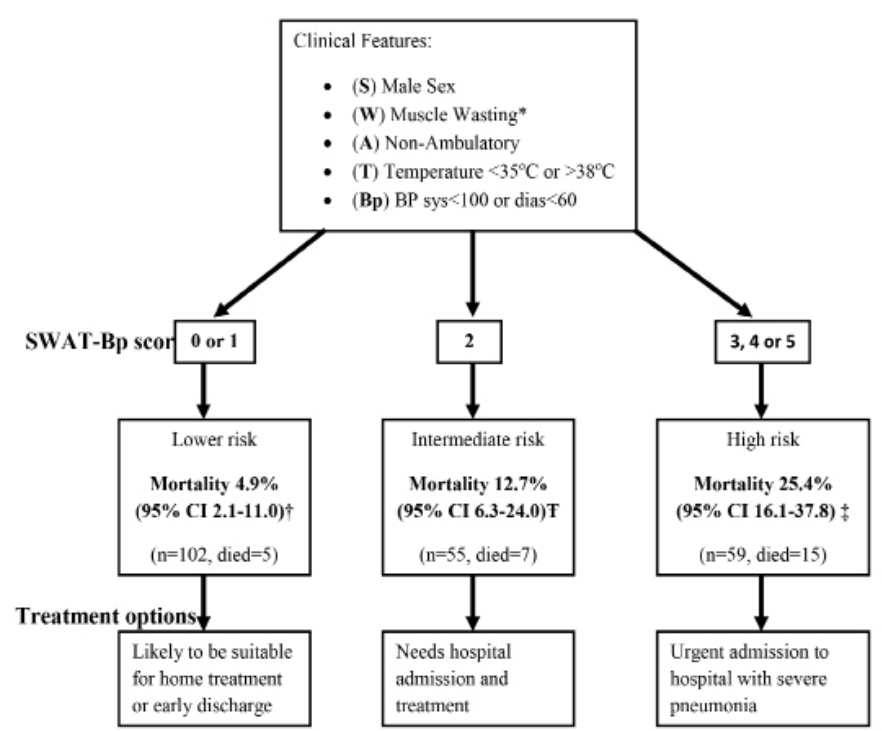

$*$ defined as mid-upper arm circumference (MUAC) $\leq 190 \mathrm{~mm}$

+ We are $95 \%$ certain that the mortality risk for a score of $<2$ is between $2.1 \%$ and $11.0 \%$

王 We are $95 \%$ certain that the mortality risk for a score of 2 is between $6.3 \%$ and $24.0 \%$

Figure 3: The SWAT-Bp score is a severity assessment tool based on five adverse clinical features, for use in a hospital setting. This one-step strategy enables stratification of patients with communityacquired pneumonia into groups according to their risk of mortality.

\section{Discussion}

This study validates the novel SWAT-Bp score which could be used to stratify patients into three risk groups. ${ }^{19} \mathrm{~A}$ SWATBp score of 0 or 1 indicates milder clinical pneumonia with $4.9 \%$ chance of mortality ( $2.2 \%$ in derivation cohort), likely suitable for outpatient management or early discharge from hospital. A score of 2 indicates moderate pneumonia with $12.7 \%$ mortality risk $(7.4 \%$ in derivation), requiring hospital admission and management. Scoring $\geq 3$ indicates severe pneumonia with one in four patients dying in-hospital (one in two in derivation), necessitating immediate hospitalisation and appropriate management. The objective variables of which the score consists are easily assessed on admission, enabling rapid triage in busy clinical settings and reducing bias, while requiring little training to administer. Differences in mortality risks from the derivation cohorts could be due to numerous factors including seasonal variation, variation in microbiological patterns and change in resources over time. Alternatives include patients lost to follow-up differing from the patients included, but these options are all speculative and therefore no definitive conclusions can be drawn. This study is conducted on in-patients and hence suggests that approximately half this population could be suitable for outpatient management or early discharge (those scoring 0 or 1). A reduction of this magnitude would be clinically and economically useful. Although the NPV for a score of 0 or 1 indicates that approximately $95 \%$ of these patients would survive, evidently, discharging all these patients with a one in 20 mortality risk would be perilous. It is important to highlight that this score is designed for pragmatic use during assessment in combination with clinical judgement. Reflecting on these statistics, one can further differentiate the management of the lower mortality risk scores. A score of 0 correlates to $0 \%$ mortality risk indicating outpatient management may be appropriate. A score of 1 indicates a relatively low risk of mortality, where caution should be heeded with discharge counselling used to facilitate early discharge. However, this score has not been validated for outpatient use and our data collection did not focus on individual management of patients whilst hospital inpatients. We can, therefore, not assume that these patients could all have been managed as outpatients as we do not know whether their survival was in part associated with provision of medical management that is unavailable in the community, such as oxygen therapy or intravenous antibiotics.

The sensitivity of a SWAT-Bp score of $\geq 2(81.5 \%)$ indicates that this score aids in identification of patients at lower risk of deterioration. Practically speaking, if patients with a score of $\geq 2$ deteriorate, they would already be in an appropriate setting in which higher level treatment may be available. The SWAT-Bp score stratifies patients with clinical pneumonia according to mortality risk, demonstrated by an AUROC of 0.744 in this study, and 0.867 in the derivation study. ${ }^{19} \mathrm{In}$ the original validation cohort of the CURB-65 and CRB-65 scores, comparatively slightly better values were obtained for sensitivity ( $75 \%$ and $80 \%$ respectively) and specificity $(75 \%$ and 61\%), as well as the AUROC for the CURB-65 (0.79) and CRB-65 (0.76) scores. ${ }^{16}$ The CURB-65 and CRB-65 scores are widely used in higher-income countries, where there is much evidence supporting their accuracy..$^{10,12,16,17}$ Despite recommendations that they should be revalidated for use in novel environments, few such studies have been reported. One study in Nigeria demonstrated strong sensitivity and specificity of the CURB-65 score, but the sample size was small (80) and HIV prevalence was low (14.3\% amongst those with known status; a high proportion did not undergo HIV testing). ${ }^{24}$ Conflicting evidence exists regarding whether pneumonia in HIV-infected patients differs from HIVnegative individuals, in terms of clinical presentation and outcome. ${ }^{25-28}$ Therefore, it may be inappropriate to apply these scores to assess pneumonia severity in Malawi, where approximately $11 \%$ of adults in the community ${ }^{29}$ and $80 \%$ of those presenting to hospital with $\mathrm{CAP}^{19}$ are infected with HIV. The CRB-65 score was found to be less sensitive (sensitivity $36.4 \%$, specificity $80.6 \%$, AUC 0.649) in stratifying patients presenting with LRTI suggestive of pneumonia in Malawi than the SWAT-Bp score. ${ }^{19}$ Patients with pneumonia in Malawi are younger; the average life expectancy is 58 years compared to 80 in the UK. ${ }^{2,29}$ Simple, rapid pneumonia severity assessment tools are needed which perform well in regions of high HIV rates and few resources. A recent study in Uganda derived a new four-point score for stratification of mortality risk among HIV-infected individuals with pneumonia. It consisted of tachycardia, tachypnoea, hypoxia and CD4 count $<50$ cells $/ \mathrm{mm}^{3}$ and stratified patients with incremental mortality risk. ${ }^{30}$ This score required limited laboratory data but only included patients who were HIV positive which is unlikely to be pragmatic.

The most significant variables from the SWAT-Bp score in predicting mortality risk are simple objective measures: males (OR 4.0) and non-ambulatory status (OR 4.1). Ambulatory (NPV 93.4\%) and female (NPV 93.7\%) patients appear to be less likely to die from pneumonia in this study population. Sex disparity has been demonstrated amongst tuberculosis patients in South Africa; a smaller proportion of female subjects provided smear-positive sputum samples than males. This was attributed to a higher index of suspicion in females and delays in health-seeking behaviours in males. ${ }^{31}$ Additionally, male sex has previously been demonstrated as an independent risk factor for severe sepsis in Malawi. ${ }^{32}$ We cannot be certain if our study findings reflect increased 
female health-seeking behaviours or whether the most unwell females never attend hospital. However, it is also worth noting that the most significant variables in the validation cohort differed from the derivation cohort, making it difficult to draw precise conclusions about the importance of each individual variable in the composite score.

\section{Strengths and limitations}

Strengths of this study include the prospective design and hence inclusion of all patients with a primary diagnosis of pneumonia on admission, despite only 127 (63.2\% of known discharge diagnoses) having a diagnosis of pneumonia at end-point. The inclusion of these patients is pragmatic and represents widespread practice in resource-limited settings. Evidently, it is clinically challenging to correctly diagnose pneumonia on admission, as demonstrated by a study in Uganda where only $9.6 \%$ of patients presenting with clinical pneumonia were confirmed bacterial pneumonia on discharge. Pulmonary tuberculosis accounted for over half of the incorrect pneumonia admission diagnoses. ${ }^{30}$ Additionally, by incorporating two separate data collection periods at different times throughout the year could help adjust for seasonality changes; it would be better to conduct data collection over an entire year to ensure more complete adjustment for this factor. To our knowledge, this is the only severity assessment score for pneumonia that has been derived and validated with two separate cohorts from a resource-limited setting with high HIV rates, rendering it a useful contribution to current research.

However, this study was primarily limited by the relatively small sample size (and hence small number of deaths) in addition to the limitation of being a single centre trial. This perhaps enables scope for revalidation in other centres in sub-Saharan Africa. The international definition of CAP is an acute infection of pulmonary parenchyma with acute infiltrate demonstrated on chest $\mathrm{x}$-ray. ${ }^{16,33}$ In this setting, universal radiological confirmation was prevented by resource limitations, especially portable radiographs for the most unwell patients. Our loss to follow-up rate of 7.5\% reflects limitations in clinical data collection, incomplete patient records systems and complicated patient flow. These factors feed into wider than envisaged confidence intervals $(61-93 \%$ for sensitivity and $44-58 \%$ for specificity at a score of $\geq 2$ ). Baseline characteristics were similar in those lost to follow-up and those included. The incorporation of community follow-up in future research would be beneficial to determine outcomes for discharged patients and enable validation of the score in an outpatient setting.

\section{Conclusion}

The SWAT-Bp score has been validated in a new population sample to predict mortality risk from clinical communityacquired pneumonia on admission to hospital in Malawi. It could be used as an adjunct to stratify patients with pneumonia into low, intermediate and high risk mortality groups, thereby aiding management decisions. It could be most useful in identification of lower-risk patients who may be suitable for early discharge or outpatient treatment. However, the score did not perform as well as in the derivation cohort.

\section{Conflicts of interest}

The authors are aware of no conflicts of interest during this study.

\section{Author contributions}

The study was planned by IB, EB, MI and JR.

The data were collected by IB and IM.

Data were analysed by IB, with assistance from JR.

The study was written up by IB, supported by advice from EB, IM, PW and JR.

\section{Funding}

This work was supported by the University of Birmingham BMedSc Intercalation fund.

\section{Acknowledgements}

The authors would like to acknowledge all the staff and patients at Queen Elizabeth Central Hospital, Blantyre, Malawi.

\section{References}

1. World Health Organization [Internet]. The top 10 causes of death. Fact sheet No 310 [cited 2016 Sept 27] Available from: www.who.int/ mediacentre/factsheets/fs310/en/

2. World Health Organization [Internet]. World Health Statistics 2013 [cited 2016 Sept 27]. Available from: www.who.int/gho/publications/world health statistics/EN WHS2013 Full.pdf?ua=13. San Joachim M, Personal communication, $20 \overline{1}$.

4. Scott JA, Hall AJ, Muyodi C, Lowe B, Ross M, Chohan B et al. Aetiology, outcome, and risk factors for mortality among adults with acute pneumonia in Kenya. Lancet. 2000; 355(9211): 1225-30. https://doi.org/10.1016/ S0140-6736(00)02089-4

5. Capelastegui A, Espaňa PP, Quintana JM, Areitio I, Gorordo I, Egurrola $\mathrm{M}$ et al. Validation of a predictive rule for the management of community-acquired pneumonia. Eur Resp J. 2006; 27(1): 151-157. doi: 10.1183/09031936.06.00062505

6. Rosón B, Carratalá J, Dorca J, Casanova A, Manresa F, Gudiol F. Etiology, reasons for hospitalization, risk classes and outcomes of communityacquired pneumonia in patients hospitalized on the basis of conventional admission criteria. Clin Infect Dis. 2001; 33(2): 158-65. https://doi. org $/ 10.1086 / 321808$

7. Rello J. Demographics, guidelines, and clinical experience in severe community-acquired pneumonia. Crit Care. 2008;12(Suppl 6): S2. doi: 10.1186/cc7025.

8. Mandell LA, Wunderink RG, Anzueto A, Bartlett JG, Campbell GD, Dean NC et al. Infectious Disease Society of America/American Thoracic Society consensus guidelines on the management of community-acquired pneumonia in adults. Clin Infect Dis. 2007; 44(Supplement 2): s27-72. https://doi.org/10.1086/511159

9. Kollef MH, Sherman G, Ward S, Fraser VJ. Inadequate antimicrobial treatment of infections: a risk factor for hospital mortality among critically ill patients. Chest. 1999; 115(2): 462-474. https://doi.org/10.1378/ chest.115.2.462

10. Neill AM, Martin IR, Weir R, Anderson R, Chereshsky A, Epton MJ et al. Community-acquired pneumonia: aetiology and usefulness of severity criteria on admission. Thorax. 1996; 51(10): 1010-1016. http://dx.doi. org/10.1136/thx.51.10.1010

11. Johnstone J, Majumdar SR, Marrie TJ. The value of prognostic indices for pneumonia. Curr Infect Dis Rep. 2008; 10(3): 215-222.

12. Fine MJ, Hough LJ, Medsger AR, Li YH, Ricci EM, Singer DE et al. The hospital admission decision for patients with community-acquired pneumonia: results from the pneumonia Patient Outcomes Research Team cohort study. Arch Intern Med. 1997; 157(1): 36-44. doi:10.1001/ archinte.1997.00440220040006

13. Loke YK, Kwok CS, Niruban A, Myint PK. Value of severity scales in predicting mortality from community-acquired pneumonia: systematic review and meta-analysis. Thorax. 2010; 65(10): 884-890. doi: 10.1136/ thx.2009.134072

14. Phua J, See KC, Chan YH, Widjaja LS, Aung NW, Ngerng WJ et al. Validation and clinical implications of the IDSA/ATS minor criteria for 
severe community-acquired pneumonia. Thorax. 2009; 64(7): 598-603. doi: 10.1136/thx.2009.113795

15. This study was organised by a subcommittee of the Research Committee of the British Thoracic Society and the Public Health Laboratory Service. Community-acquired pneumonia in adults in British hospitals in 19821983: a survey of aetiology, mortality, prognostic factors and outcome. QJM: An International Journal of Medicine. 1987; 62(3): 195-220. https:// doi.org/10.1093/oxfordjournals.qjmed.a068093

16. Lim WS, Van der Eerden MM, Laing R, Boersma WG, Karalus N, Town GI et al. Defining community acquired pneumonia severity on presentation to hospital: an international deviation and validation study. Thorax. 2003; 58(5): 377-382. http://dx.doi.org/10.1136/thorax.58.5.377

17. Marras TK, Gutierrez C, Chan CK. Applying a prediction rule to identify low-risk patients with community-acquired pneumonia. Chest. 2000; 118(5): 1339-1343. https://doi.org/10.1378/chest.118.5.1339

18. Zuberi FF, Khan JA. Prospective comparison of prediction rules of mortality risk for CAP in a developing country. Int J Tuberc Lung Dis. 2008; 12(4): 447-452.

19. Birkhamshaw E, Waitt CJ, Innes M, Waitt PI. Severity assessment of lower respiratory tract infection in Malawi: Derivation of a novel index (SWAT-Bp) which outperforms CRB-65. PLoS ONE. 2013; 8(12): e82178. doi: 10.1371 journal.pone. 0082178

20. Rylance J, Waitt PI. Pneumonia severity scores in resource poor settings. Pneumonia. 2014; 5(1): 30-37. https://doi.org/10.15172/pneu.2014.5/481

21. Levy ML, Le Jeune I, Woodhead MA, Macfarlane JT, Lim WS; British Thoracic Society Community Acquired Pneumonia in Adults Guideline Group. Primary care summary of the British Thoracic Society Guidelines for the management of community acquired pneumonia in adults: 2009 update. Prim Care Resp J. 2010; 19(1): 21-27. doi: 10.4104/pcrj.2010.00014

22, Ferro-Luzzi A, James WP. Adult malnutrition: simple assessment techniques for use in emergencies. Br J Nutr. 1996; 75(1): 3-10.

23. Feldman C, Alanee S, Yu VL, Richards GA, Ortqvist A, Rello J et al. Severity of illness scoring systems in patients with bacteraemic pneumococcal pneumonia: implications for the intensive care unit care. Clin Microbiol Infect. 2009; 15(9): 850-857. doi: 10.1111/j.1469-0691.2009.02901.x.

24. Mbata GC, Chukwuka CJ, Onyedum CC, Onwubere BJ. The CURB65 scoring system in severity assessment of Eastern Nigerian patients with community-acquired pneumonia: a prospective observational study. Prim Care Respir J. 2013; 22(2): 175-80. doi: 10.4104/pcrj.2013.00034.

25. Malinis M, Myers J, Bordon J, Peyrani P, Kapoor R, Nakamatzu R et al. Clinical outcomes of HIV-infected patients hospitalized with bacterial community-acquired pneumonia. Int J Infect Dis. 2010; 14(1): e22-e27. doi: 10.1016/j.jijid.2009.03.001.

26. Salami AK, Olatunji PO, Oluboyo PO, Akanbi AA $2^{\text {nd }}$, Fawibe EA. Bacterial pneumonia in the AIDS patients. West Afr J Med. 2006; 25(1): 1-5.

27. Feldman C, Klugman KP, Yu VL, Ortqvist A, Choiu CC, Chedid MB et al. Bacteraemic pneumococcal pneumonia: impact of HIV on clinical presentation and outcome. J Infect. 2007; 55(2): 125-135. https://doi. org/10.1016/j.jinf.2007.04.001

28. Madeddu G, Fiori ML, Mura MS. Bacterial community-acquired pneumonia in HIV-infected patients. Curr Opin Pulm Med. 2010; 16(3): 201-207. doi: 10.1097/MCP.0b013e3283375825

29. Chalmers JD, Singanayagam A, Hill AT. Predicting the need for mechanical ventilation and/or inotropic support for young adults admitted to the hospital with community-acquired pneumonia. Clin Infect Dis. 2008; 47(12): 1571-4. doi: 10.1086/593195.

30. Koss CA, Jarlsberg LG, den Boon S, Cattamanchi A, Davis JL, Worodria W et al. A clinical predictor score for 30-day mortality among HIV-infected adults hospitalized with pneumonia in Uganda. PLoS ONE. 2015; 10(5): e0126591. doi: 10.1371/journal.pone.0126591

31. Austin JF, Dick JM, Zwarenstein M. Gender disparity amongst TB suspects and new TB patients according to data recorded at the South African Institute of Medical Research laboratory for the Western Cape Region of South Africa. Int J Tuberc Lung Dis. 2004; 8(4): 435-9.

32. Waitt PI, Mukaka M, Goodson P, SimuKonda FD, Waitt CJ, Feasey N et al. Sepsis carries a high mortality among hospitalised adults in Malawi in the era of antiretroviral therapy scale-up: a longitudinal cohort study. J Infect. 2015; 70(1): 11-19. doi: 10.1016/j.jinf.2014.07.004

33. Johnson PDR, Irving LB, Turnidge JD. Medical Journal of Australia practice essentials - infectious disease. 3: Community-acquired pneumonia. Med J Aust. 2002; 176(7): 341-7. 